\title{
Motivational Interviewing for Poorly Controlled Type 2 Diabetics in a Rural South African Community
}

\author{
Yolanda Barnard ${ }^{1}$, Anthea Lesch ${ }^{2}$, Tony Cassidy ${ }^{3}$ \\ ${ }^{1}$ Medical Doctor, Cape Town, South Africa \\ ${ }^{2}$ Stellenbosch University, Cape Town, South Africa \\ ${ }^{3}$ Department of Child and Family Health Psychology, Ulster University, Coleraine, Northern Ireland \\ *Corresponding Author: Dr. Tony Cassidy, School of Psychology, Ulster University, Cromore Road, Coleraine, \\ BT52 1SA, North Ireland, E-mail: t.cassidy@ulster.ac.uk
}

Received: 12 October 2018; Accepted: 22 October 2018; Published: 01 November 2018

\begin{abstract}
Difficulty adhering to lifestyle changes required for effective management is rife among patients with Type 2 Diabetes Mellitus (T2DM). Motivational interviewing may prove a useful tool for healthcare providers when supporting patients. Thirteen poorly controlled T2DM patients, 11 females and 2 males, took part in the study. A qualitative design with semi-structured interviews was used and the data was analysed by means of thematic analysis. Themes explored included Stumbling blocks to change, awareness of difficulties, making changes, and the role of motivational interviewing. Motivational Interviewing was received positively and provided useful information, which will help to understand the needs of the diabetic in a rural community as well as suggest recommendations for improving future clinic care.
\end{abstract}

Keywords: Motivational interviewing; Diabetes; Qualitative

\section{Introduction}

Diabetes Mellitus is a group of metabolic conditions characterised by raised blood glucose levels. Whereas patients with type 1 diabetes are usually diagnosed in childhood and insulin-dependent, type 2 diabetes (T2DM) develops later in life and is responsible for the vast majority of cases of this chronic condition. T2DM is the focus of this 
study. It is a worrying fact that the incidence and prevalence of T2DM are on the increase globally, in particular in developing countries [1]. In 2011 it was estimated that approximately two million people were living with diabetes in South Africa [2]. An audit of T2DM in Cape Town's public sector in 2011 revealed that almost $80 \%$ of patients' diabetes was uncontrolled (HbA1c >7\%) [3]. More recently, the 2015 mortality report indicated that diabetes is the second highest cause of natural deaths in South Africa and the number one cause in the Western Cape province [4].

Failure to manage diabetes adequately is associated with an increased risk of complications, including nephropathy, neuropathy, retinopathy and cardiovascular disease [5]. More specifically, an $\mathrm{HbAlc}$ of more than $7.5 \%$ is associated with a two point five to fivefold greater relative risk of developing microvascular complications [6], which may potentially have a huge impact on quality of life. Many diabetic patients only receive help when they already have complications, placing an enormous burden on the healthcare system, which translates into an economic burden as well [7]. Furthermore, according to Inzucchi et al. [1], T2DM is also associated with and implicated in, among others, an increased risk of cancer, earlier cognitive decline and dementia, chronic liver disease and accelerated arthritis.

Despite the fact that diabetic care in the primary health care setting in South Africa has been prioritised with clear guidelines put in place, this disease remains a challenge due to difficulty in adhering to lifestyle and behavioural changes required to promote effective management. As these important behavioural changes are multiple as well as complex, there is a need for interventions which are helpful in promoting self-management of the disease [8]. According to Booth, et al. [9], some known barriers to self-management of T2DM include difficulty in changing established habits, a lack of knowledge, understanding and motivation as well as barriers relating to social circumstances and the practicalities of making lifestyle changes. Frandsen et al. [10] found that T2DM patients report that they have received insufficient information about their disease and treatments and that dietary advice received was vague. Also, the reasons behind lifestyle and dietary advice had not been clearly explained to the patients who participated in this study.

Research has found that healthcare professionals tend to view diabetes in a more serious light than patients [11] and that a partnership as well as improved communication between the healthcare professionals and their patients is needed to overcome the gap in how the severity of the disease is understood. According to Stewart et al. [12] the relationship between the patient and the healthcare provider plays an important role in understanding the illness and adherence to medication. The approach endorsed by the National Institute for Health and Care Excellence [13] states that patients should be part of the decision-making process regarding blood glucose control. Philips et al. [14] also noted that working with patients on an individual basis to find out what they can manage with regards to their diabetes care is crucial.

According to Miller [15], ambivalence about behaviour change is often the central problem, manifested in a lack of motivation. Exploring ambivalence entails weighing the advantages and disadvantages of current behaviour against 
intended behaviour and this may prove to be useful in the process of bringing about change [15]. The impact of motivational interventions on HbA1c levels has been studied in recent years and further research in this regard is warranted [5]. Rollnick, et al. [16] has recommended Motivational Interviewing (MI) as a guiding approach to bring about lifestyle change and self-care.

MI is a cognitive-behavioural technique which aims to assist patients in identifying and changing behaviours which may be preventing optimal management of a chronic condition, such as T2DM [17]. It focuses on patients formulating reasons for change as well as providing assistance with resolving ambivalence about changing their behaviour. A facilitator guides this process and helps with setting goals for behaviour change [15]. The facilitator aims to be a partner to the client during this process. This method can be used with patients at any stage of change, including those who are not at all motivated to implement change as well as highly motivated patients. The MI approach is very different from the traditional health education model which is used in most disease management approaches, where sharing of information, giving advice and scare tactics usually make up the core of the interaction [18]. A systematic review by Rubak, et al. [19] found that MI performs better than traditional advice-giving in $80 \%$ of studies.

The purpose of the present research was to assess, by means of qualitative interviews, the usefulness of MI as a novel, non-confrontational approach in the primary care setting, where traditional interactions have historically been the norm. It served as an introduction to MI and explored how participants related to this technique. The research also sought to dig deeper into the world of the diabetic to understand which factors limit blood sugar control and explore possible self-management options. Furthermore, the role of socioeconomic circumstances with regards to disease control was also investigated. The study endeavored to provide a unique opportunity for gaining insight with a clinician-researcher conducting the research.

\section{Method}

\subsection{Design}

A qualitative research design puts the researcher in the position to function as the primary instrument for the collection and analysis of information [20]. In order to understand the diabetic in context, the student researcher in this particular study placed herself in a position to be a participant in the generation of data [21]. This research design enabled the researcher to fulfill the research aims, namely introducing the participants to some MI techniques as well as gaining an insider's view of the world of the diabetic to understand barriers to adherence and the role of socio-economic circumstances in the research context. Furthermore, a unique view on patient-doctor communication was sought.

\subsection{Participants}

The research participants were drawn by purposive sampling from a population of T2DM patients who receive their chronic medication at a rural clinic in South Africa. At their six-monthly doctor's visit their blood results were 
reviewed and those who had at least two HbAlc results of more than $8 \%$ were asked to participate. The final sample included 13 poorly controlled T2DM patients. Their demographics were as follows: Eleven females, ages ranging from 45 to 66 years and two males, ages 45 and 64 years. Participants have been known with T2DM for between five and 15 years.

\section{Materials}

An interview guide was developed from the Community Care of North Carolina Motivational Interviewing (MI) Resource Guide [22], which is a manualised approach to the principles, tools and techniques of MI. Motivational Interviewing techniques were used to explore the world of the diabetic in greater detail. Some examples of techniques utilised during the interview included: Agenda Mapping, by means of which obstacles to proper diabetes management were discussed and barriers to change were explored. Further motivation to think about change was introduced with the DARN CAT technique, where the following questions were asked:

- Desire: What do you want to do to improve your blood sugar?

- Ability: What do you think you can do?

- Reason: Why might you make that change?

- Need: Why is this important for your health?

- Commitment: Will you do it?

- Activation: Are you prepared?

- Taking steps: Need to provide information

\section{Procedure}

When all ethical approvals were granted, each of the potential candidates was personally visited by the researcher at their homes. They were informed of the study and asked whether they would be willing to be a participant. Each willing candidate was given the Information Sheet and Consent Form. The interview took place in the participant's own home on a weekday afternoon or Saturday morning, whichever suited both the participant and the researcher. It took between 30 and 45 minutes and was recorded with a voice recorder.

Four out of a potential 17 candidates were not available, due to work or travelling engagements at the time of the proposed interviews, which resulted in a final sample of 13 participants. The translation of the Interview Schedule from English to Afrikaans was done by the researcher, who is fully bilingual with her first language being Afrikaans. The interviews were done in Afrikaans and the transcriptions were translated to English. In order to ensure their accuracy and acceptable language use, all translated documents were verified by Dr. Lesch.

\subsection{Data analysis}

The study data was analysed using a thematic approach in the tradition of Braun, et al. [23]. 


\subsection{Ethical considerations}

Ethical approval was granted by the University of Ulster's Research Ethics Committee, as well as Pharma-Ethics and the National Health Research Ethics Committees in South Africa.

\section{Results}

The results are presented in the form of quoted interview transcripts. The interviews revealed a number of barriers to behavioral change, which are discussed under the theme of stumbling blocks. Awareness with regards to various aspects of diabetes as well as changes already made is further themes which emerged from the interviews. Lastly, the role of MI is discussed. Table 1 below outlines the main themes and sub-themes which describe the participants' experiences of living with diabetes.

\begin{tabular}{|c|c|c|}
\hline Main theme & Sub-theme & Quote \\
\hline \multirow{7}{*}{$\begin{array}{l}\text { Stumbling } \\
\text { blocks }\end{array}$} & Sweet tooth & "A little bit more sugar, sweet things, I cannot resist it" \\
\hline & $\begin{array}{l}\text { Misunderstanding of fruit } \\
\text { sugar }\end{array}$ & $\begin{array}{l}\text { "We always have access to fruit...I eat the fruit of the } \\
\text { season" }\end{array}$ \\
\hline & $\begin{array}{l}\text { Daily challenges of adapting } \\
\text { to a healthier way of eating }\end{array}$ & $\begin{array}{l}\text { "We live far from the town, so you buy for your health, } \\
\text { but when the salad stuff is finished, you need to wait until } \\
\text { Saturday when you go into town again" }\end{array}$ \\
\hline & $\begin{array}{l}\text { Role of the family/members of } \\
\text { the household }\end{array}$ & $\begin{array}{l}\text { "but it is difficult, because you have a family for which } \\
\text { you need to cook...they don't like the food you eat" }\end{array}$ \\
\hline & $\begin{array}{l}\text { Lack of willpower/poor self- } \\
\text { control }\end{array}$ & $\begin{array}{l}\text { "I don't know what happened that I started using sugar } \\
\text { again" }\end{array}$ \\
\hline & Invisible nature of diabetes & "You don't feel anything, but it already caused damage" \\
\hline & Awareness of responsibility & "I must eat right and leave the sweet things" \\
\hline \multirow[t]{3}{*}{ Awareness } & $\begin{array}{l}\text { Lacking personal } \\
\text { accountability }\end{array}$ & "The artificial sweetener has an aftertaste" \\
\hline & Knowledge gap & "Now what would this protein consist of?" \\
\hline & Awareness of complications & $\begin{array}{l}\text { "...not everybody lose their limbs, but the organs inside } \\
\text { fail" }\end{array}$ \\
\hline \multirow{3}{*}{$\begin{array}{l}\text { Making changes } \\
\text { already }\end{array}$} & Making an effort & "Yes, I drank a lot of fizzy drinks, but I cut down" \\
\hline & Feeling the benefit & $\begin{array}{l}\text { "Now that I have cut out the starch, now my sugar is } \\
\text { automatically better" }\end{array}$ \\
\hline & Positive experience & "It is an interesting conversation, very helpful" \\
\hline \multirow[t]{2}{*}{ Role of MI } & Goal setting & "I will have to walk in the mornings" \\
\hline & Support & $\begin{array}{l}\text { "It's good to know that there are other people who are } \\
\text { interested, who helps you, so you just need to do your part } \\
\text { as well" }\end{array}$ \\
\hline
\end{tabular}

Table 1: Theme and sub-theme summary.

\subsection{Stumbling blocks}

5.1.1 Sweet tooth: It became clear from the interviews that many diabetics have a sweet tooth, which stands in the way of their blood glucose control. This appears to be experienced almost as a biological need, or an addiction to 
sweet foods. These sweets and chocolates were also seen as treats and are readily available as there are multiple small convenience "home shops" in the community which sell these items.

01: "I eat the sweet snacks...it's as if I have to eat something sweet....I just crave sweet stuff" (F;56).

03: "A little bit more sugar, sweet things, I cannot resist it" (F;61).

12: "No I won't be able to leave it, but I can make it less....because I'm so fond of my chocolates...I'm so used to it" $(\mathrm{M} ; 64)$.

5.1.2 Misunderstanding fruit sugar: While sweets and chocolates were clearly recognised as to be avoided, the sweet content of fruit was perhaps less well understood. Furthermore, fruit is freely available to this community and many people grow their own fruit in their home gardens. Participants indicated that, due to the abundant availability of fresh fruit, it would be difficult for them to limit its intake.

02: "We always have access to fruit....I eat the fruit of the season...also grapes, but I find it too sweet....Yellow peaches and melon, currently eating these....Watermelon I love" (F;54).

09: "Probably eat too many fruits at a time, I don’t eat one peach, I will eat three....I eat a lot of watermelon" (F;53).

11: "I eat more than one fruit a day" (F;50).

5.1.3 Daily challenges of adapting to a healthier way of eating: This community is relatively poor and finances determine what food can be bought. Transport is needed to get to fresh produce, such as salad items and fresh vegetables in the closest town, 22 kilometers from Goedverwacht and most residents do not have their own vehicle. People have to make choices on what they can afford and what is easily available.

02: "I buy low GI bread when I have money....The food that a diabetic should eat is not expensive, it's just, if you have nothing in your house, then you eat the things that you would not usually eat" (F;54).

04: "If I buy separate diabetic foods, I will have to cook separately and at the end of the day it will be much more expensive" (F;58).

06: "We live far from the town, so you buy for your health, but when the salad stuff is finished, you need to wait until Saturday when you go into town again" (F;63).

5.1.4 Role of the family/members of the household: The subtheme relating to family members seems to be complex. In some instances they can be helpful, for example when the diabetic is encouraged to make better choices.

03: "Mommy may not eat that.... When I visit my family, they don't use sugar. They tell me you're not supposed to, but I'm naughty" (F;61).

09: "Mommy shouldn't take so much (of the chocolate)" (F;53). 
On the other hand, some family members stand in the way of the diabetic making lifestyle changes. It also appears as though they are unsympathetic towards the diabetic's experience. Diabetic patients tend to have the notion that they need to prepare separate meals - with "diabetic food" for themselves and "normal food" for the rest of the household.

03: "The paper she (the dietician) gives you is just for you, the other people in the house will not eat it (F;61).

06: "But doctor you are at home and you feel so alone, because they don't understand how you feel...because you feel so tired today, you're not in the mood for anything...you need to do your work. They don't have any sympathy with you, as you are not bedbound" (F;63).

13: "But when the child sits there with the slab of chocolate...my mouth waters" (F;52 ).

When the diabetic is a woman, she is often the person who cooks. Her food choices need to be acceptable to the rest of the household. There is often an extended family living in one house, which complicates matters even further. Items such as sugar-free cool drinks are not accepted by most non-diabetics.

04: "I know which are the right choices, but I don't buy them, because the others in the house must also eat" (F;58). 06: "But it is difficult, because you have a family for which you need to cook...they don't like the food you eat" (F;63).

13: "Definitely the Coke Zero - I see it standing in the fridge, they will not drink it...their cool drink is long finished, then I still have Tab left, because it doesn't taste nice.”(F;52).

Then there is the unique view of a diabetic who has an improved diet when she is not at home (where her co-diabetic mother is the cook).

07: "The person who cooks the food, that is the biggest problem, because you need to eat the person's food. When I'm at college, I make my own food....then I will cut out starch completely" $(F ; 45)$.

As a whole, it seems as if the amount of encouragement and support from family members is quite variable.

5.1.5 Lack of willpower/poor self-control: There is knowledge regarding the correct diet, but many participants admit to weakness with regards to keeping to it.

03: "At that time I didn't drink coffee, only tea with some milk and no sugar...I don't know what happened that I started using sugar again" $(\mathrm{F} ; 61)$.

04: "When they bring watermelon, I won't eat just a little piece, I eat a whole ring....I admit that I have lost track" (F;58).

05: "I know I eat the wrong food" $(\mathrm{F} ; 66)$. 
5.1.6 Invisible nature of diabetes: There are often no symptoms when the blood glucose levels are raised. This invisible nature of the condition complicates control. Patients respond to visible signs and symptoms and are therefore possibly more concerned when the blood glucose level is low.

04: "When I really feel unwell is when the sugar is low" $(\mathrm{F} ; 58)$.

09: “Once I was at the clinic and my sugar was 27, I couldn't believe it. You don't feel anything, but it already caused damage" $(\mathrm{F} ; 53)$.

5.1.7 Awareness: The awareness theme manifests at various levels, including assuming responsibility on the one hand, but lacking personal accountability on the other. A knowledge gap becomes clear when analysing the data. Awareness regarding complications and advising others regarding diabetes are other aspects which are discussed.

5.1.8 Awareness of responsibility: During the interviews it was apparent that the participants are aware of their responsibility with regards to the control of their blood glucose levels.

01: "I must eat right and leave the sweet things" (F;56).

02: "People expect the doctor to heal them, you need to heal yourself...you need to work on it yourself, this I know" $(\mathrm{F} ; 54)$.

04: "It (the diabetic information) is sufficient, the patient just needs to be more serious about it....has to be more focused on eating correctly" $(\mathrm{F} ; 58)$.

5.1.9 Lacking personal accountability: Participants offer various explanations to questions regarding lifestyle changes and improved choices, which could be indicating a lack of taking responsibility for the condition.

02: "Often when they check my sugar then I have just eaten....many diabetics don't eat the day before they go to the clinic, I will always eat my breakfast" (F;54).

05: "The artificial sweetener has an aftertaste" (F;66).

12: "Sometimes I get offered cool drink when I work somewhere, then I drink the Coke" (M;64).

5.1.10 Knowledge gap: Some responses and questions indicated poor knowledge regarding food choices. The participants who had already seen the dietician are much clearer and more confident to make the correct choices. It is unfortunate that despite having been a diabetic for many years, a number of the participants have not yet seen the dietician. They need to rely on dietary advice and information given to them by health care workers, family members and friends on an informal basis, as well as what they read and see on television. This information is general in nature with the focus on simple carbohydrates which needs to be avoided. 
02: "I bought Kellogg's Corn Flakes, I will lie on the bed and eat a bowl filled with it, without milk, as a snack" (F;54).

04: (after explaining that a fruit should be eaten with a protein-containing food) "Now what would this protein consist of?" (F;58).

10: "So the extra sugar in the coffee, tea and porridge is also a problem?....Is Coke Zero okay?" (M;45).

Some participants used the interview as an opportunity to ask questions, which indicates that diabetics think about their condition and that there is a need to raise concerns about the illness and get rid of misconceptions.

08: "About the sugar in fruit - does the body work differently with that type of sugar than with normal sugar?....and the vegetables which grow under the ground?" $(F ; 57)$.

13: "Is diabetes inherited?....So what causes the illness?....Are there different types of diabetes?.... Why should the insulin be kept in the fridge?" (F;52).

5.1.11 Awareness of complications: Each and every participant is well aware of the possible complications of diabetes. This is a small community and most residents know each other. Most of them are known with family members or loved ones who are already suffering from complications.

02: “One has long term plans and we all know the outcome if you don't look after yourself - amputated legs....and in the end you are a burden for everybody and you don't have that ability to mobilise...I don't see that for myself" $(\mathrm{F} ; 54)$.

06: "I have seen how diabetes can affect your organs...not everybody lose their limbs, but the organs inside fail" (F;63).

08: "The other doctor has probably told me three times already that my kidneys will be the cause of my death" (F;57).

09: "My mom had sugar, my dad's family also had sugar, my dad's and the sisters' legs were both amputated" (F;53).

A related comment, but one which really sums up the underlying emotion associated with the condition:

04: "Nowadays I don't want to attend a funeral of a diabetic, it's too emotional for me" (F;58).

It is also noted that there is awareness to advise children, grandchildren and others regarding diabetes.

06: "Now at my house they drink fizzy drinks, but none of them has sugar, but I talk a lot. I told them I have sugar, so you can also get it, you can inherit it" (F;63).

08: "My son, he is not a diabetic yet, but I wish I had all the information that he has access to today....Change your lifestyle if you want to live, change your lifestyle that it's not an issue for you (advice for newly diagnosed 
diabetics)....My mom was also a diabetic, she never told us not to eat this or that, but today I can advise my child, whether he listens or not" (F;57).

5.1.12 Making changes already: On a positive note, several participants are able to give examples of changes already made with regards to dietary habits. This shows that change is possible in this community.

5.1.13 Making an effort: 08: "When I make a cooked meal, it's either rice or potato" (F;57).

10: "Yes, I drank a lot of fizzy drinks, but I cut down" (M;45).

11: "I use Equal (an artificial sweetener) in my coffee and tea" (F;50).

5.1.14 Feeling the benefit: Those who already reap the benefits of changes made relate the improvements to their changed eating habits.

02: "There was I time I drank a lot of sugar and when I stopped it, the pins and needles feeling in my feet went away" (F;54).

07: "Now that I have cut out the starch, now my sugar is automatically better" (F;45).

\subsubsection{Role of MI}

Positive experience: This study was the first encounter this community had with Motivational Interviewing techniques. The feedback received indicated that the participants viewed the interview in a positive light.

05: "Yes, it once again made us aware of what lies ahead and what we should eat and how we look after ourselves" (F;66).

13: "It is an interesting conversation, very helpful" (F;52).

Goal setting: During the interview, patients were prompted to think about a possible goal which they could start implementing immediately, in order to improve blood sugar levels.

09: "I am aware, but now I also know I must start again with my veggies" (F;53).

11: "I will have to walk in the mornings" $(\mathrm{F} ; 50)$.

Support: Most participants were able to think of a change they would be willing to make, but they needed guidance in this regard. It seems as if a partner is needed to start making a change, which fits with the spirit of MI.

05: "I will walk, but unfortunately I'm one of those who needs to be taken by the hand" (F;66).

08: "It's good to know that there are other people who are interested, who helps you, so you just need to do your part as well" (F;57).

\section{Discussion}

It appears from the interviews that eating habits are an important factor which impacts negatively on this specific diabetic community. Some changes are already being made and participants display a willingness to improve their 
eating habits. Patients need knowledge of proteins, carbohydrates and fats with practical examples of good food and snack choices. Planning meals in advance and buying the correct choices of food when doing monthly or weekly shopping is a very important aspect. This may indicate that the dietician possibly has a bigger role to play in helping people breed the correct eating habits, whilst providing more practical support in this regard. People need to be able to confidently cook a healthy meal which the diabetic as well as the rest of the household can eat.

Available finances determine what food can be bought and once again the dietician's advice should take this into account. Diabetics should be aware which non-perishable foods are good choices and encouraged to keep these in stock. The low GI bread mentioned by one of the participants is an example of a more expensive, but healthier, product which is bought when finances allow. This also brings in a political element of whether Governments should provide subsidies for diabetic friendly food.

Family members and other people in the diabetic's household, while not well-informed, will be a chronic stumbling block. These people need to be involved in the care of the diabetic. Helping them to understand the illness, its complications and how they can improve the outcome of the fellow member who is a diabetic, may be a priceless venture. Family members are often unaware of the relation between eating habits and long term complications. Education is the key. Involving those in the diabetic's social context in lifestyle improvement training would benefit all parties concerned. Logistically, this will not be an easy task. On a positive note, there is evidence that some family members already influence the diabetic in a positive manner by raising awareness regarding wrong food choices.

An unfortunate reality of diabetes is that high blood glucose levels often go unnoticed and the complications which develop are invisible until a late stage. All participants in this study are well aware of the outcomes of the condition, but still fail to manage their blood glucose levels. This confirms previous research which has indicated that being informed of the risks of unhealthy behaviour is not sufficient to change to a healthier pattern [17]. There is a definite need for more information and to discuss issues related to diabetes. One properly planned information session at diagnosis will be a priceless venture. An information leaflet with an explanation of the condition and basic aspects with frequently asked questions answered in advance will be extremely useful. Short informative videos and educational talks in the waiting room of the clinic are more examples of information-sharing opportunities which can be utilised. An informed patient will be better able to confidently manage his or her condition.

This study's findings are in keeping with previous studies which revealed that many South Africans follow poor diets as a result of poor nutritional knowledge, financial constraints and limited access to healthy food, among others [24]. Ideally, this community needs Health Promoters to work with diabetic patients to educate and improve their skills regarding self-management. These individuals need a secondary school education up to at least Grade 8. Once they are employed, they receive additional training in knowledge and skills which will enable them to deliver health education messages and promote health [25]. They could be trained in MI techniques and can receive basic, specific 
and practical dietary education which could enable them to work in a supportive function with the dietician. Unfortunately, the currently available Home Based Careers do not have sufficient background knowledge to fulfill such a task. A proposal in this regard should be handed to the appropriate authorities.

In this study MI was utilised in an informal manner, as an interview technique rather than an intervention technique. The impact of the techniques may have been greater had the sessions been done by a trained practitioner. Further research into MI with sessions guided by a trained facilitator as well as a possible intervention study may be explored in future.

\section{Conclusion}

The study served as an introduction to some MI techniques in this specific community, where the only available diabetes care service is the clinic. It was well received by the participants and provided useful information to the researcher, which enabled her to make some recommendations with regards to future clinic care. It offered the participants the opportunity to reflect on their diabetes in a novel manner. Furthermore, the study also indicated that most participants are eager to think and talk about diabetes and to make improvements to their lifestyle. MI may be useful in this community for various reasons: Exploring ambivalence by means of formal MI may prove helpful in addressing the current lack of willpower to keep on track with lifestyle changes. Furthermore, helping patients focus on strengths and reflect on times when they have successfully made changes in the past may promote self-efficacy, which in turn may improve willpower and personal accountability. Setting goals may help patients take control of the condition and encourage self-management.

It would be unrealistic to expect a diabetic in a rural community to have an ideal diet and perfect blood glucose control. Prioritising dietician appointments and providing the correct dietary as well as lifestyle management information is of paramount importance. Prompting the diabetic to take ownership of the condition and encouraging improved self-management skills whilst providing support and creating a partnership is possible. Health Promoters who practice MI techniques may help to fulfill this need, whilst health care providers aim to incorporate the spirit of $\mathrm{MI}$ in their daily clinic care.

\section{References}

1. Inzucchi S, Bergenstal R, Buse J, et al. American Diabetes Association, European Association for the Study of Diabetes. Management of hyperglycemia in type 2 diabetes: a patient-centred approach: position statement of the American Diabetes Association (ADA) and the European Association for the Study of Diabetes (EASD). Diabetes Care 35 (2012): 1364-1379.

2. Butler N. National guidelines at a glance: type 2 diabetes mellitus. Professional Nursing Today 15 (2011): 41-45.

3. De Vries E, De Sa A, Murie M, et al. Auditing chronic disease care: does it make a difference? Presentation at the 15th National Family Practitioners Conference, Cape Town (2012). 
4. Statistics South Africa. Key findings: P0309.3 - Mortality and causes of death in South Africa: Findings from death notification (2015).

5. Jones A, Gladstone BP, Lubeck M, et al. Motivational interventions in the management of HbA1c levels: A systematic review and meta-analysis. Primary Care Diabetes 8 (2014): 91-100.

6. Stratton IM, Kohner EM, Aldington SJ, et al. UKPDS 50: Risk factors for incidence and progression of retinopathy in Type II diabetes over 6 years from diagnosis. Diabetologia 44 (2001): 156-163.

7. Bradshaw D, Norman R, Pieterse D, et al. The South African Comparative Risk Assessment Collaborating Group (2007). Estimating the burden of disease attributable to diabetes in South Africa in 2000. South African Medical Journal 97 (2000): 700-706.

8. Ekong G, Kavookjian J. Motivational interviewing and outcomes in adults with type 2 diabetes: A systematic review. Patient Education and Counseling 99 (2016): 944-952.

9. Booth AO, Lowis C, Dean M, et al. Diet and physical activity in the self-management of type 2 diabetes: barriers and facilitators identified by patients and health professionals. Primary Health Care Research and Development, 14 (2013): 293-306.

10. Frandsen KB, Kristensen JS. Diet and lifestyle in type 2 diabetes: the patient's perspective. Practical Diabetes 19 (2002): 77-80.

11. Clark M, Hampson SE. Comparison of patients' and healthcare professionals' beliefs about and attitudes towards type 2 diabetes. Diabetic Medicine 20 (2003): 152-154.

12. Stewart M. Effective physician-patient communication and health outcomes: A review. Canadian Medical Association Journal 152 (1995): 1423-1433.

13. Miller WR, Rollnick S. Motivational Interviewing: Preparing People to Change Addictive Behaviour. New York: Guilford Press National Institute for Health and Care Excellence (NICE) (2015). Clinical Guideline 28: Type 2 diabetes in adults: management. National Institute for Health and Clinical Excellence (1991).

14. Phillips A. Optimising the person-centered management of type 2 diabetes. British Journal of Nursing 25 (2016): 535-538.

15. Rollnick S, Miller WR. What is motivational interviewing? Behavioural and Cognitive Psychotherapy 23 (1995): 325-334.

16. Rollnick S, Miller W, Butler C. Motivational interviewing in health care: Helping patients change behaviour. London: Guilford Press (2008).

17. Bundy C. Changing behaviour: using motivational interviewing techniques. Journal of the Royal Society of Medicine 97 (2004): 43-47.

18. Butterworth SW, Linden A, McClay W. Health coaching as an intervention in health management programs. Disease Management \& Health Outcomes 15 (2007): 299-307.

19. Rubak S, Sandbæk A, Lauritzen T, et al. Motivational interviewing: a systematic review and meta-analysis. British Journal of General Practice 55 (2005): 305-312.

20. Terre Blanche M, Durrheim K, Painter D. Research in Practice: Applied Methods for the Social Sciences. Cape Town: University of Cape Town Press (2006). 
21. Michie S, Abraham C. Health Psychology in Practice. Oxford: Blackwell Publishing (2004).

22. Community Care of North Carolina Motivational Interviewing (MI) Resource Guide. Retrieved from https://www.communitycarenc.org/media/files/mi-guide.pdf

23. Braun V, Clarke V. Using thematic analysis in psychology. Qualitative Research in Psychology 3 (2006): 77-101.

24. Ebriham Z, De Villiers A, Ahmed T. Factors influencing adherence to dietary guidelines: a qualitative study on the experiences of patients with type 2 diabetes attending a clinic in Cape Town. Journal of Endocrinology, Metabolism and Diabetes of South Africa 19 (2014): 76-84.

25. Mash B, Levitt N, Steyn K, et al. Effectiveness of a group diabetes education programme in underserved communities in South Africa: pragmatic cluster randomized control trial. BMC Family Practice 13 (2012): 126.

Citation: Yolanda Barnard, Anthea Lesch, Tony Cassidy. Motivational Interviewing for Poorly Controlled Type 2 Diabetics in a Rural South African Community. Archives of Clinical and Medical Case Reports 2 (2018): 168-181.

This article is an open access article distributed under the terms and conditions of the Creative Commons Attribution (CC-BY) license 4.0 